\title{
Higher Incision at Upper Part of Lower Segment Caesarean Section
}

\author{
Yong Shao, 'Meena Pradhan' \\ 'The First Affiliated Hospital of Chongqing Medical University, Chongqing, PR China.
}

\section{ABSTRACT}

Introduction: To determine if the upper part of the lower segment of the uterus is a better site for cesarean incision then the traditionally used lower end.

Methods: This is a case-control study (1:1 ratio) conducted from $1^{\text {st }}$ October $2012-30^{\text {th }}$ September 2013 observed between transverse incision at the upper part of the lower segment versus traditional lower segment of the uterus. Two hundred caesarean sections were performed via a transverse uterine incision at the upper part of the lower segment and equal numbers of uterine incision was performed at traditional lower segment. To obtain less intraoperative bleeding high incision made at thicker wider muscular part at of the upper part of lower segment about 2-3 cm distances from vesico-uterine serosa.

Results: The estimated volume of blood loss in high incision $188 \pm 60.1 \mathrm{ml}$ was significantly less compared to traditional incision $330.1 \pm 86.5 \mathrm{ml}(\mathrm{p}<0.05)$. Duration of operation $30.5 \pm 6.6$ minute versus $45.3 \pm 7.2$ minute and tearing the uterine incision was significantly less with the high incision versus traditional incision. Other procedural and patient benefits are noted.

Conclusions: An incision at the upper part of the lower segment reduces blood loss, enhances uterine retraction, predisposes to fewer complications, is easier to repair, precludes bladder adhesion to the suture line and reduces operation time.

Keywords: caesarean section; higher incision technique; traditional uterine incision technique.

\section{INTRODUCTION}

In the history of caesarean section, low segment vertical incision was described by Kronig B in 1912, now has been rarely applied in clinical practice. ${ }^{1}$ With the modified technique, low transverse uterine incision was recommended by Kerr JMM in $1926 .{ }^{2}$ After about 64 years surgical practice on Kerr traditional incision technique to deliver abdominally, in 1990, Zhou JiJie and Stephanie Zhou ${ }^{3}$ observed that a high incision conserves an active uterine retraction mechanism and is less prone to excessive blood loss. They found that site that best suit their purpose was at about $2-3 \mathrm{~cm}$ above the upper part of the lower segment. ${ }^{5}$ Blood loss during a traditional incision caesarean operation ranges heavy (about $12 \%$ of the patients $<500 \mathrm{ml}$ of bleeding to an average of $400 \mathrm{ml}$ )..$^{2,4-6}$

The question is why blood loss in a traditional incision caesarean delivery is high and is there an alternative approach that may reduce blood loss? We aimed to apply

Correspondence: Shao Yong, The first Affiliated Hospital of Chongqing Medical University, You yi Road, Chongqing Medical University, 400016, China. Email: cqshaoyong@163.com, Phone: +86 13101280793 . 
further modified technique first introduced by Zhou JiJie in China and both incision techniques were observed as case-control study.

\section{METHODS}

The ethics committee of the First Affiliated Hospital of Chongqing Medical University approved study. In our study group, all of our patients had primary caesarean sections and all patients provided written informed consent prior to our study participation. A total of 400 patients with both incision techniques were enrolled in the study. Eligible patients included aged was between 24- 35 years, with a mean age of 27.1 years. Their gestational ages were between 35- 42 weeks. Among the 200 patients who received the high incision procedure, 46 were primi gravidae and 96 were multiparity. Indications for caesarean section were cephaolpelvic disproportion in 58 cases. In a control group of 200 patients, who had caesarean section by the tradition incision, with comparable age, parity, gestational weeks and indications, were selected for study. We two authors involved in this study, first author who had surgical skill and experience, performed the operations employing both techniques and second author assisted all the operative procedures. The assignment of the patients, procedural technique and assistant were random. Patients with placenta previa, previous caesarean section, accidental hemorrhage, twin pregnancy or fetus exceeding $4 \mathrm{~kg}$ birth weight were excluded.

We investigated the various aspects of the procedure and patient's benefit after applying high incision technique versus traditional incision surgical procedure at lower segment site. Thus, the comparative study was initiated from $1^{\text {st }}$ October 2012 to $30^{\text {th }}$ September 2013 and involved performing 200 cases group CS for high incision technique and 200 control group CS for traditional incision technique.

In study group, patients were positioned in antiTrendelenberg conjunction with the first assistant closing the gap between the abdominal wall and the upper uterine edge to prevent inflow of amniotic fluid into the peritoneal cavity. Anti-Trendelenberg position also reduces the pressure on lower edge of the incision by the fingers which were engaged in prying open the incision, thus reducing the danger of laceration. To obtain less blood loss, high incision made at thicker wider muscular part at the upper part of lower segment about 2-3 cm distances from vesico-uterine serosa (Figure 1).

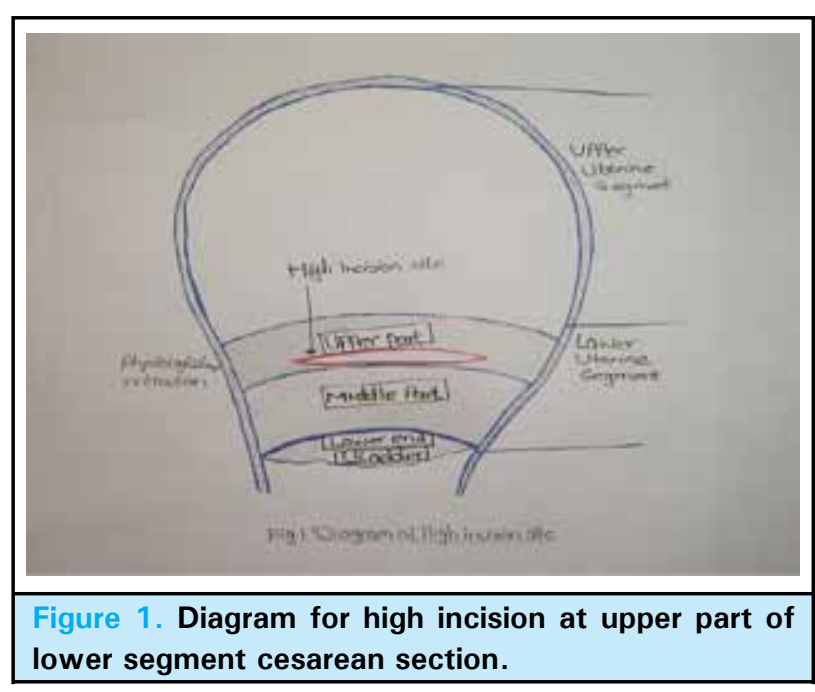

Gravid uterus is divided into two parts: upper uterine segment and lower uterine segment at term gestation. Lower segment further hypothetically divided into three parts: Upper part, middle part and lower part (vesicouterine serosa) where retroperitoneal and superior border of bladder is attached. Bladder flap is untouched in high incision technique. Moreover, high incision does not push down the peritoneum. Scalpel was used to nick over much strong muscular retraction area of the upper part of lower segment and forceps was used to puncture uterine cavity to drain and suctioned amniotic fluid. Blunt lateral extension of incision to slow delivery of cephalic or breech version. After delivery of fetus, Allis forceps applied to clamp bilateral incision angle and placenta delivered by control cord traction. Incision closed in two layers.

In control group, patient was kept in Trendelenberg position. Traditional incision made through the thin, noncontractile portion of the lower uterine segment in a curvilinear fashion. The lower flap of peritoneum is elevated, and the bladder flap is gently separated by blunt or sharp dissection from the underlying myometrium to push down and expose the lower uterine segment. Distance from the bladder to the incision site was < $1 \mathrm{~cm}$. All the operation was carried out under epidural anaesthesia. Some of the procedural differences are noted (Table 1).

Measurement of estimate blood loss during the operation was recorded. The abdominal pads soaked with blood were collected by squeezing in to a measuring plastic jug. Blood loss from the abdominal and uterine incisions, from uterine atony, from hematoma, from tearing of the large blood vessels, and that due to taking more than 2.5 minutes to deliver the fetal head with fingers ${ }^{7}$ was measured as described by Bullough , ${ }^{8}$ Yuen ${ }^{9}$ and Zhu. ${ }^{10}$

For statistical analysis, we used SAS 19.3 version 
student's t-test. Results are expressed as mean $\pm \mathrm{SD}$. $p<0.05$ was considered statistically significant.

\section{RESULTS}

We studied in 400 cesarean section including both high incision and traditional incision dividing into two groups. In study group $(n=200)$ cesarean section was high incision technique and in control group $(n=200)$ was traditional incision. During applying each procedure we found high incision technique is superior to traditional incision (Table 1).

The average weight of the newborns in the high incision group was $3340 \pm 218 \mathrm{~g}$, and that of the newborns in the traditional incision group $3328 \pm 223 \mathrm{~g}$. Thus, there is no marked differences in the birth weight, $p>0.05$. Birth weight, therefore, does not influence the volume of blood loss in the two groups. However, in the study group there was significant less blood loss $(198 \pm 60.1 \mathrm{ml})$ was recorded compared to control group (330.1 $\pm 68.5 \mathrm{ml}$ ) (Table 2). Time consumption in high incision is much shorter than traditional incision procedure.

Comparisons of other important variables are also illustrated (Table 3). Advantages and disadvantages are distinct between high incision group and traditional incision group.

\begin{tabular}{|c|c|c|}
\hline Variable & $\begin{array}{l}\text { Standard traditional incision } \\
\text { technique (7) }\end{array}$ & High incision technique \\
\hline Dextro-rotation of uterus & Looked for and corrected & Not necessary \\
\hline Operation table position & Trendelenberg & Anti-Trendelenberg \\
\hline Peritoneum and uterine incision & $\begin{array}{l}\text { Cut and strip down the } \\
\text { retroperitoneal of the bladder, then } \\
\text { make the traditional incision }\end{array}$ & $\begin{array}{l}\text { Short transverse incision } 2-3 \mathrm{~cm} \text { above } \\
\text { upper part of lower segment, aspirate all } \\
\text { the amniotic fluid, then extend laterally. }\end{array}$ \\
\hline Fetal head delivery & $\begin{array}{l}\text { Begin delivery without waiting for } \\
\text { complete release of liquor }\end{array}$ & "Easy-does-it" * fetal head delivery \\
\hline $\begin{array}{l}20 \text { units of intrauterine Oxytocin } \\
\text { after the second stage }\end{array}$ & Yes & Yes \\
\hline $\begin{array}{l}\text { Lifting up uterine incision edges } \\
\text { with haemostatic clamp }\end{array}$ & Yes & Unnecessary in this technique \\
\hline $\begin{array}{l}\text { Closing uterus with continuous } \\
\text { suture in } 2 \text { layers }\end{array}$ & Yes & $\begin{array}{l}\text { Yes, but visceral peritoneum and the } \\
\text { superficial layer are sutured together } \\
\text { simultaneously }\end{array}$ \\
\hline Visceral peritoneum & Closed separately & As in row above \\
\hline $\begin{array}{l}\text { Pre-closure routine to examine } \\
\text { uterus, adnexa, hemostasis }\end{array}$ & Yes & Yes \\
\hline $\begin{array}{l}\text { Abdominal closure with } \\
\text { continuous suture }\end{array}$ & $\begin{array}{l}\text { The parietal peritoneum, each } \\
\text { of the rectus sheaths layers, the } \\
\text { fat layers, and the skin layer is } \\
\text { separately closed }\end{array}$ & $\begin{array}{l}\text { Parietal peritoneum left open, Deep } \\
\text { layer of anterior sheaths and fat layer. } \\
\text { Superficial layer of subcutaneous layer }\end{array}$ \\
\hline Blood collected in the vagina & $\begin{array}{l}\text { Insert gloved hand into vagina to } \\
\text { remove the blood }\end{array}$ & $\begin{array}{l}\text { Fundal pressure to push out blood } \\
\text { collected in the vagina }\end{array}$ \\
\hline
\end{tabular}

* Taking as much as a minute or longer if the fetus is estimated at $>3.6 \mathrm{~kg}$ birth weight, to get the head out of the uterine incision, then delivered with a forceps blade assisted by fundal pressure 


\begin{tabular}{|llll|}
\hline \multicolumn{4}{l}{ Table 2. Comparison of major variation between traditional incision group vs. high incision group. } \\
\hline Variables & Traditional incision $(\mathrm{n}=200)$ & High incision $(\mathrm{n}=200)$ & $\mathrm{p}$-value \\
Age & $33.9 \pm 5.1$ & $32.8 \pm 5.5$ & $\mathrm{NS}$ \\
Gravidity & $3.1 \pm 1.6$ & $3.8 \pm 1.9$ & $\mathrm{NS}$ \\
Gestational age (week) & $37.3 \pm 3.8$ & $35.3 \pm 4.1$ & $\mathrm{NS}$ \\
Pre-operative hemoglobin $) \mathrm{g} / \mathrm{dl})$ & $11.5 \pm 1.5$ & $10.6 \pm 2.0$ & $\mathrm{NS}$ \\
Post-operative hemoglobin & $8.2 \pm 1.5$ & $9.7 \pm 1.7$ & $\mathrm{NS}$ \\
Fetal weight & $3328 \pm 223 \mathrm{~g}$ & $3340 \pm 218 \mathrm{~g}$ & $\mathrm{NS}$ \\
Blood loss (ml) & $330.1 \pm 68.5 \mathrm{ml}$ & $198 \pm 60.1 \mathrm{ml}$ & $\mathrm{p}<0.05$ \\
Torn incision & 8 & 0 & $\mathrm{p}<0.05$ \\
Low apgar scores & 11 & 3 & $\mathrm{P}<0.05$ \\
Duration of operation in minutes & $45.3 \pm 7.2 \mathrm{~min}$ & $30.5 \pm 6.6 \mathrm{~min}$ & $\mathrm{p}<0.05$ \\
\hline
\end{tabular}

Table 3. Comparison of other variables between traditional incision vs. high incision group.

\begin{tabular}{|lll|}
\hline Variables & Traditional incision $(\mathbf{n}=\mathbf{2 0 0})$ & High incision $(\mathbf{n}=\mathbf{2 0 0})$ \\
Floating heads & 11 fetus & 0 \\
Uterine atony & $5(2.5 \%)$ & 0 \\
Thickness of incision edges at the time & Lower edge 2-6 mm think and upper & $10-12$ mm at both edges \\
of closure & edge $6-10 \mathrm{~mm}$ thick & \\
Oozing from needle holes & $116(58 \%)$ patients & 0 \\
Hematoma at incision angles & $18(9 \%)$ & 0 \\
$\begin{array}{l}\text { Distance from the bladder to the incision } \\
\text { line }\end{array}$ & $<1 \mathrm{~cm}$ & $2-3 \mathrm{~cm}$ \\
$\begin{array}{l}\text { Blood transfusion } \\
\text { Postoperative hemorrhage }\end{array}$ & $10(5 \%)$ & 0 \\
$\begin{array}{l}\text { Re-admission into the hospital for late } \\
\text { postpartum hemorrhage }\end{array}$ & $2(1 \%)$ & 0 \\
\hline
\end{tabular}

Notes: The suture material used in both groups for uterine and abdominal closure was \#2 polyglycolic sutures with a strong round-body needle of $48 \mathrm{~mm}$ curvature length.

\section{DISCUSSION}

Over the recent years abdominal delivery has dramatically increasing as safe surgical mode of child birth worldwide and it has sensitized a numbers of controversial issues as well. Recently, in China overall caesarean sections rate has strikingly increased from $3.8 \%$ in 1988 to $39.3 \%$ in 2008 year. Moreover, $11.3 \%$ in county site and $64.1 \%$ in the city with a vast variation in 2008 was disclosed. ${ }^{11}$ Additionally, postpartum haemorrhage is still a leading cause of maternal death has significantly dropped to $27.8 \% .{ }^{12}$ Certainly, it might be due to advance health care facilities in China.

There are several factors involved from maternal request for caesarean delivery could be daunted by labour pain, 'precious baby' due to advanced age or assisted reproductive conception such as in vitro fertilization (IVF), due to history of habitual abortion, if succeed to near term elective termination is demanded to prevent unwanted events during vaginal procedure such as arrest of descent, prolonged latent/active phase of labour, fetal distress, maternal distress, etc. Maternal request is accepted in most of the developed and developing countries. Financial status of women is also another possible factor to choose mode of delivery especially by planned caesarean section.

The rate of rupture of a uterine scar from a previous traditional incision in future labour averages about 1/200. In the United States, vaginal birth after caesarean delivery (VBAC) has declined from $28.3 \%$ in 1996 to $12.6 \%$ in $2002 .{ }^{13}$ The rapid decline of VBAC might be due to distrust in the healing of the traditional incision. The edges of a high incision, as in the results above, are amenable to healing composed of muscular 
tissues instead of fibrous tissue principally because of their equal thickness and accurate coaptation of two edges. Precise apposition, in theory, promotes physiological healing. ${ }^{14,15}$ If a uterine incision heals so that it is composed of histologically normal muscles, and if incision infection and anaemia are prevented, rupture of the scar in future labour may be reduced. The thicker layer at this location supplies more nutrients, contributing towards healthier healing. The muscular part has the same characteristic to $s$

tretch as muscles in other areas of the uterus. Therefore, a high incision could be a step forward to safer VBAC and much less likely to develop bladder adhesion and placenta previa etc. in subsequent pregnancy. Both edges of the incision are of same thickness $10-12 \mathrm{~mm}$, length of incision is usually $8-8.5 \mathrm{~cm}$. In a traditional incision, it is far less easy to accurately appose edges of unequal thickness. If inaccurate apposition were to cause everting incision surfaces at some parts of the suture line, proper healing may be compromised. The risk of future uterine rupture is an unknown.

Uterine laceration and heavy bleeding of a traditional incision is unavoidable if fetal weight is $>4 \mathrm{~kg}$. The incision's two ends to extend laterally does not prevent all laceration because at first, the incision is located at the lower and thinner part of the lower segment, and secondly, the physical width at the traditional incision location limits the length of incision stretch. Avoidance reached $100 \%$ in the high incision group, as in the results above shows the higher, thicker and wider part of the lower segment with stronger retractile muscles, and allows about $38 \mathrm{~cm}$ circumference fetal head to deliver outside is easy without being laceration. Similarly, there is no extended tear and heavy bleeding during delivery of an impacted fetal head, as seen in the result above. The same reasons given above, in addition to a smaller fetal head circumference due to moulding, explain the absence of complication.

Occasionally, a patient with secondary postpartum haemorrhage readmitted into the hospital after a traditional incision caesarean delivery. If no retained placenta or membranes, and no infection can explain the cause of bleeding, then haemorrhage could be explained on the basis of an abnormal uterine retraction mechanism at incision site. The poor retraction would begin from the time of intra-operative bleeding-induced anemia, at the much thinner leaner vascular layer, leading to poor incision healing. No patient in our study group was re-admitted for treatment of secondary postpartum hemorrhage. This is probably due to less intra-and postoperative blood loss as a result of an active retraction mechanism and much thicker richer vascular layer at this location.
Urine leaking from the vagina after a traditional incision caesarean operation occurs infrequently. In the results above, the lower edge of a traditional incision before closure could be $<1 \mathrm{~cm}$ from or next to the bladder. Bladder flap hematoma is another complication of traditional incision technique because bladder flap is injured from detachment of vesico-uterine space leading to bleeding at the uterine suture. ${ }^{16}$ In their report, ten symptomatic women were successfully treated with laparoscopic procedure. However in our study no bladder flap hematoma was observed in control group. Additionally, injury to the bladder leading to fistula formation does occur rarely during closure of a traditional incision. In contrast, the lower edge of a high incision is about $2-3 \mathrm{~cm}$ distance from the bladder before closure, and the completed closure is at least about 2-2.5 cm far away from the bladder, making a bladder flap hematoma and fistula extremely unlikely with a high incision.

The traditional incision creates "floating or extended fetal head", which is made well below the leading part of a fetal head. As a head remains floating above the opening of a traditional incision, improvised maneuvers to deliver the head tear the incision infrequently and result in more blood loss, especially if a prolapsed umbilical cord is present at the same time. In the case of a high incision, the incision location coincides with the level of the ear of fetal head. The incision location is exactly the same as for a head engaged in the pelvis. The head fills the incised opening so that there is no room to spare for a cord prolapsed. The fetal head is thus prepared for normal delivery.

Correcting dextro-rotation of the uterus has never been completely successful in reducing blood loss in a traditional incision caesarean delivery. The two ends of the incision may still cut venous plexus or blood vessels on the lateral side of the lower segment. This is due to the incision being situated in a segment only about $8 \mathrm{~cm}$ wide, closer to the lateral uterine vessels, containing a fetal head whose circumference is from 34 to $>36 \mathrm{~cm}$, and often covered by superficial varices. An incision at the high location would be at wider less dextro-rotated part of the lower segment without superficial lateral vessels (Table 1). Besides, the location provides powerful retractile muscles to close off the injured capillary vessels. Thus, looking for and correcting dextro-rotation is not necessary in a high incision location, even if a head circumference is $>36$ $\mathrm{cm}$.

Transverse or breech deliveries occasionally can be injurious in traditional incision because of the incision location being far away from the fetal small parts. A whole hand must be inserted to reach and catch the small parts, there by risking laceration. The larger the 
hand of the surgeon is, the greater is the risk. Delivery can be made safer by moving the incision to that high location. This is explained by the incision being closer to the fetal small parts, besides being immediately adjacent to an ultra-low abdominal incision. The small parts can be reached by fingers alone to manipulate delivery without causing laceration.

Delivering a fetal head via a traditional incision without knowing the location of the occiput occasionally causes complications, e.g., tearing the incision, dealing with aftermaths of laceration, and more blood loss. Yet finding a posterior occiput and then rotating it anteriorly often tears the incision. No laceration, however, occur in our high location group, because a high incision instantly makes occiput location visible. If the right ear is visible with the incision, the occiput is on the left side. Neither manual exploration nor rotation of the occiput is necessary. Delivery is by normal methods.

It may be difficult to access the traditional incision edges for closure, particularly in a patient whose bladder has been detached. The second assistant must retract the lower abdominal flap to expose the incision edges. Overzealous retractions often exert undue pressure of the bladder, and causes haematuria in the next few hours. Traumatic access is occasionally seen when lifting up the incision edges with haemostatic clamps could tear the edges. The clamps may often be annoying, e.g., crisscrossing, getting in the way of suturing. Bladder flap hematoma may develop. In a high incision, holding up the incision edges to facilitate repair is unnecessary, since the middle part and the ultra-low uterine incision are immediately one below the other. Uterine edges are usually free from oozing (Table 1). Blood that is seen bleeding up from the uterus stops completely when closure is halfway through the deep layer. Difficult and traumatic access is therefore another reason to consider relocating the incision. Besides, blood loss and operating time is less compare to traditional incision (Table 2).

The closer the traditional incision location is to the detached bladder, the greater the injury to the lateral large blood vessels, and the worse the uterine atony. Although the earliest signs of uterine atony are recognizable, uterine atony could not be totally avoided in traditional incision deliveries (Table 3). Pre-uterine atony signs though present bring about less blood loss in our high incision deliveries (Table 2). Reduced blood loss signifies thick and well-retracted muscles clamping down the injured capillary vessels and vessels in the vascular layer, no injury to the large blood vessels, and prophylactic prevention of bleeding while making the initial short uterine incision. By prophylactic prevention of bleeding, it is meant pressing against the edges of the initial short uterine incision so that the vascular layer does not bleed profusely. All of the mean active retraction mechanism is in force. Active retraction is apparent when a high incision is $<10 \mathrm{~cm}$ long, and has 10-12 mm thick edges with exact coaptation between two surfaces, so favours the pattern of wound healing. Active retraction prevents uterine atony and postpartum hemorrhage.

Operation time cannot be reduced too much below a mean average. This can be understood by analyzing time spent at different stages of the procedure. During a traditional incision caesarean section, time has to be spent to deal with some large or small complications and their aftermaths, and on awkward accessing and closing of the uterine incision edges. Additional time has to be spent on hemostasis while opening the abdomen, on checking and correcting dextro-rotation, on clearing up the para-colic gutters before closing the abdomen, and on the cumbersome chore of layered uterine or abdominal closure. In a high incision location, the time spent looking after the above complications and their aftermaths was almost negligible, and the time spent in releasing all of the fore and after amniotic fluid was rarely more than $1 \frac{1}{2}$ minutes. While opening the abdomen, the high incision technique emphasizes applying pressure on the skin and fat layers to stop bleeding or oozing, and blunt dissection to open the fat layer rapidly.

\section{CONCLUSIONS}

Caesarean deliveries performed using the traditional incision generally succeeds without incident. However, there are some inherent risks with this procedure that occasionally may lead to complications of varying severity. Undoubtedly, we believe that the results indicate in the high incision would be an alternative surgical technique widely acceptable method in most caesarean section. We would therefore strongly recommend to obstetrician worthy of applying high incision technique that reduces blood loss, enhances uterine retraction, predisposes to fewer complications, is easier to repair, precludes bladder adhesion to the suture line, and reduces operation time.

\section{ACKNOWLEDGEMENTS}

Our special thanks to Dhana Kumar Pradhan, Mr. Sher Bahadur Pradhan, Mrs. Shanti Pradhan, Dr. Rabindra Muni Bajracharya, Miss Aishwarya Bajracharya for kind support. 


\section{REFERENCES}

1. Kronig B. Trasperitonealer cervikaler Kaiserschnitt. In Doderlein A, Kronig B, editors: Operative Gynakologie. 1912. p. 879 .

2. Kerr JMM. The technique of caesarean section with special reference to the lower uterine segment incision. Am J obstet Gynecol. 1926;12:729.

3. Zhou J, Zhou S. New concept technique in cesarean section. People Health publishing Co, Beijing. 2001;43.

4. Aladjem S. editor. Obstetrical Practice. St. Louis: Mosby; 1980. p. 754.

5. Cunningham FG, Hauth JC, Leveno KJ, Gilstrap L III, Bloom SL, Wenstrom KD. Williams Obsetrics, $22^{\text {th }}$ Edition. McGraw-Hill Copmanies, 2005. p. 587.

6. Laegeforen TN. Hemorrhage after Cesarean section [Bloding ved keisersnitt]. 2000;10(120):2864-6.

7. Zhaou H, Cui JJ, Wang DZh. Time delay between uterine incision and delivery, its influence on the newborn. Zhong Hua Hu Li Za Zhi. 1993;28:67.

8. Bullough CW, Msuku RS, Karonde L. Early suckling and postpartum hemorrhage: Controlled trial in deliveries by traditional birth attendants. Lancet. 1989;2:522-5.

9. Yuen PM, Chan NST, Yim SF, Chang AM. A randomized double blind comparison of syntometrine and syntocinon in the management of the third stage of labor. Br J Obs Gyn. 1995;102:377-80.
10. Zhu MK, Yin DY. Measurement of blood loss during normal delivery and 24 hours postpartum. Hong Hua Hi Li Za Zhi. 1985;20:10-2.

11. Feng $\mathrm{XL}, \mathrm{Xu} \mathrm{L}$, Guo $\mathrm{Y}$, Ronsamans $\mathrm{C}$. Factors influencing rising caesarean section rates in China between 1988 and 2008. Bull World Health Organ. 2012;90:30-9A .

12. Zhou YY, Zhu J, Wang YP, Dai L, Li XH, Li MR, et al. Trends of maternal mortality ratio during 1996-2010 in China. Zhonghua Yu Fang Yi Xue Za Zhi. 2011;45:934-9.

13. Center for Disease control and prevention, National center for health statistics, National vital statistic report. Vol52, no.10, 2003.

14. Williams JW. A critical analysis of 21 years' experience with cesarean section. Bull Johns Hopkins Hos. 1921;32:173.

15. Schwarz O, Paddock R, Bortnick AR. The cesarean section scar: An experimental study. Am J Obstet Gynecol. 1938;36:962.

16. Tinelli A, Malvasi A, Vittori G. Laparoscopic treatment of post-cesarean section bladder flap hematoma: A feasible and safe approach. Minim Invasiv Ther Allied Technol. 2009;18:356-60. 